\title{
The Effect of Early Initiation of Breastfeeding on Neonatal Mortality among Low Birth Weight in Aceh Province, Indonesia: An Unmatched Case Control Study
}

\author{
Satrinawati Berkat and Rosnah Sutan \\ Department of Community Health, University Kebangsaan Malaysia, Malaysia \\ Correspondence should be addressed to Satrinawati Berkat; satrin_aceh@yahoo.com
}

Received 30 April 2014; Revised 3 October 2014; Accepted 8 October 2014; Published 11 November 2014

Academic Editor: Peng Bi

Copyright (C) 2014 S. Berkat and R. Sutan. This is an open access article distributed under the Creative Commons Attribution License, which permits unrestricted use, distribution, and reproduction in any medium, provided the original work is properly cited.

\begin{abstract}
Background. Early initiation of breastfeeding is the breastfeed that is received by the baby within the first hour of birth. It is recommended to reduce infant mortality and illness. Objective. To assess the effect of early initiation of breastfeeding on neonatal mortality for low birth weight in Aceh province, Indonesia. Method. In this qualitative study unmatched case controls were used as the design. Data was collected in 8 districts in Aceh province, Indonesia, between January and December 2012. The total sample for this study was 500 LBW who were born between 2010 and 2012, subdivided into 250 LBW who died in neonatal period and 250 LBW who survived during neonatal period. Result. Thermal care and hygienic practice were not significantly associated with neonatal mortality among LBW. Feeding and early initiation of breastfeeding were associated. Discussion. Early initiation of breastfeeding had an effect on neonatal mortality for the low birth weight in Aceh province, Indonesia. The risk of mortality was decreased for those neonates who accepted breast milk within the first hour after birth. Therefore it is concluded that a new strategy to promote and improve the coverage of the initiation of breastfeeding is needed.
\end{abstract}

\section{Introduction}

Breastfeeding has many health benefits for both the mother and infant. To reduce infant mortality and ill health, the mother first provides breast milk to her infant within one hour of birth-referred to as "early initiation of breastfeeding" [1]. This ensures that the infant receives the colostrum ("first milk") [1]. Colostrums: there are ninety known components of the colostrum and two primary benefits. The two primary benefits are immune factors and growth factors. Colostrum also contains vitamins, minerals, and amino acids needed by the neonates [2].

There is growing evidence of the significant impact of early initiation of breastfeeding, preferably within the first hour after birth, on reducing overall neonatal mortality [3]. It ensures that skin-to-skin contact is made early on, an important factor in preventing hypothermia and establishing the bond between mother and child. Early initiation of breastfeeding also reduces a mother's risk of postpartum hemorrhage, one of the leading causes of maternal mortality [3]. Colostrum, the mother's milk during the first postpartum days, provides protective antibodies and indispensable nutrients, essentially acting as a first immunization for newborns, strengthening their immune system and reducing the chances of death in the neonatal period [3].

Optimally, the baby should start to breastfeed before any routine procedure (such as bathing, weighing, umbilical cord care, and administration of eye medications) is performed [4]. Early breastfeeding and skin-to-skin contact helps with better temperature control of the new-born baby, enhances bonding between the mother and the baby, and also increases the chances of establishing exclusive breastfeeding early and of its success [4]. These treatments should be more rigorously adhered to infants with low birth weight, because they are more vulnerable to diseases than those of normal weight [4].

LBW (low birth weight) is defined as a birth weight of less than 2500 grams [5]. The LBW are categorized into preterm births, intrauterine growth restriction (IUGR), and neonates 


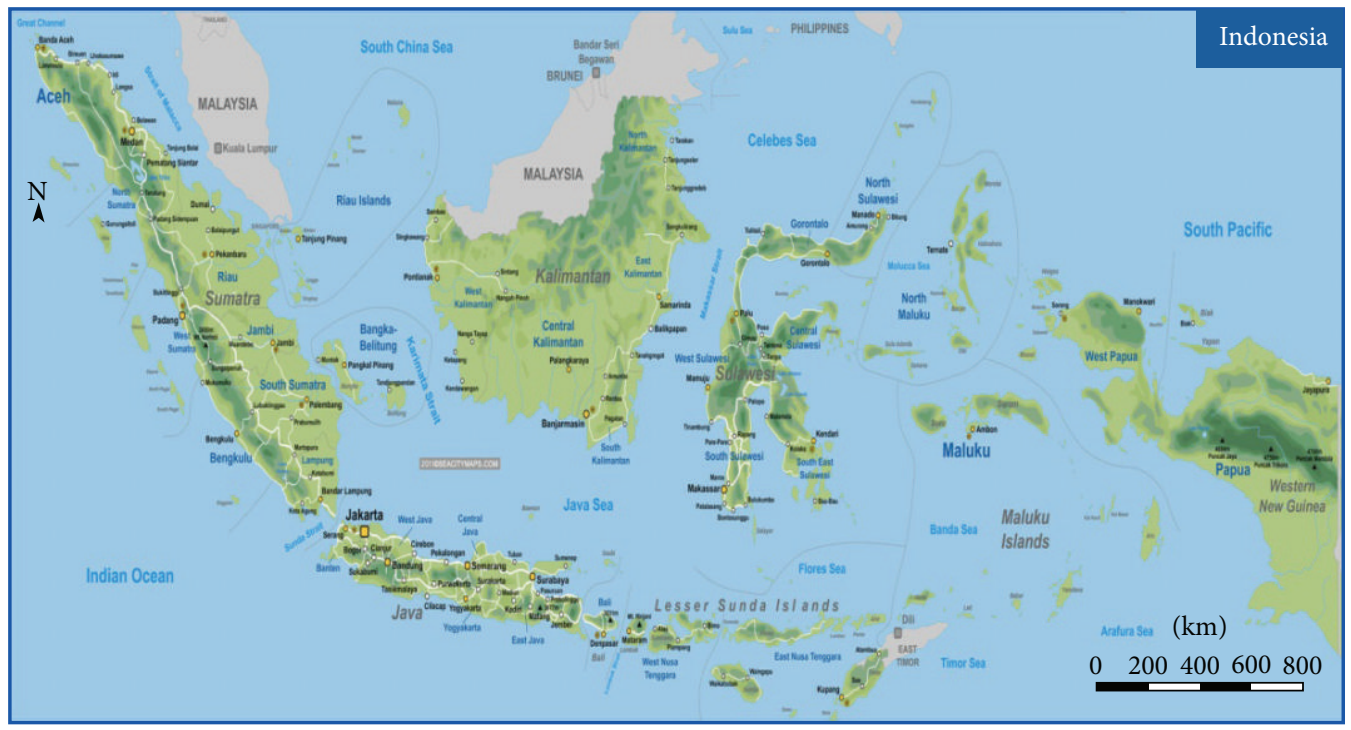

Figure 1: Aceh province in the western end of Indonesia.

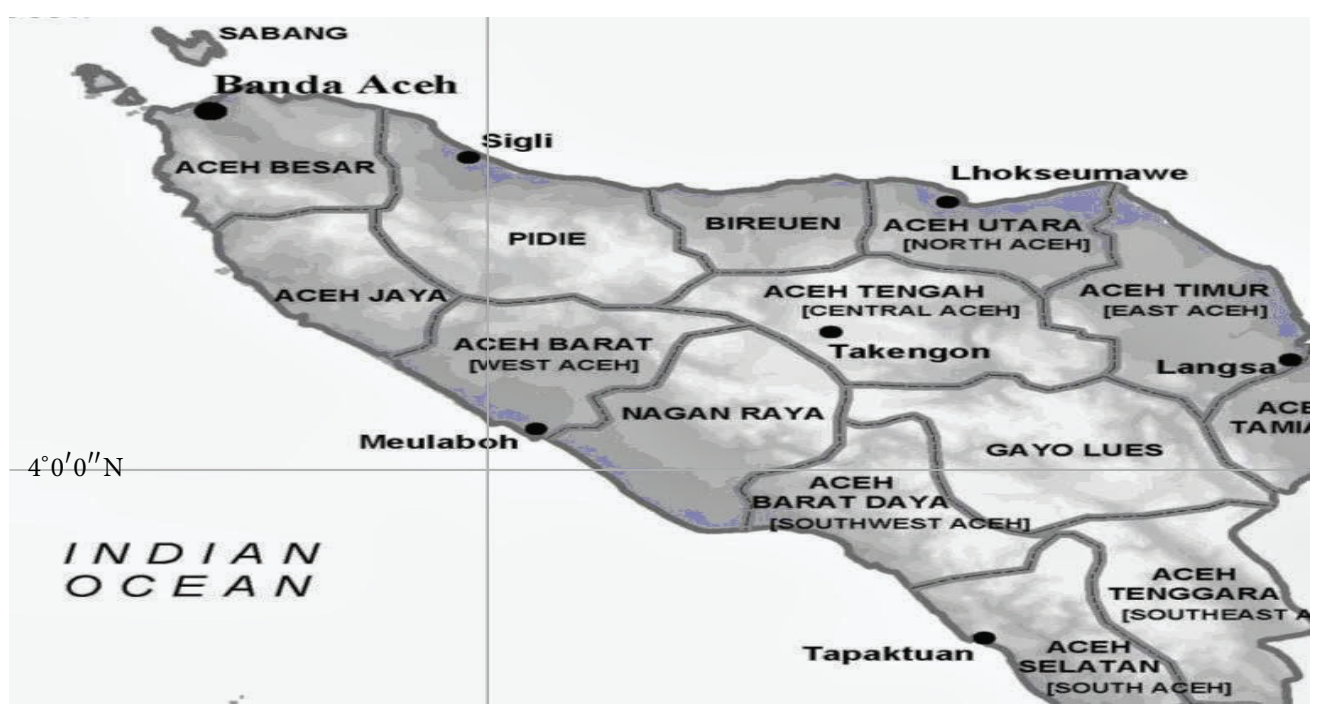

FIGURE 2: Districts in Aceh Province and 8 of 23 districts as the study site.

who are both preterm and growth restricted [6]. LBW will greatly affect the growth and development of the child. The effect does not only influence the child's younger years, but it will continue for its whole life cycle [6]. LBW, especially preterm birth complications, is the major cause of neonatal mortality in the world (35\% of all neonatal mortality) [7]. Prevalence rate for the LBW worldwide between 2007 and 2011 was $15 \%$ of all live births, and the percentage of LBW in Indonesia (Figure 1) in 2011 was $9 \%$ of 4.3 million live births [8]. The Indonesia Ministry of Health reported that premature births were the second highest cause of early neonatal mortality in Indonesia (32.4\% of all neonatal mortality) [9].

Even though the early initiation of breastfeeding is recommended and there is some evidence to show the relationship between early initiation of breastfeeding and neonatal survival $[10,11]$, the percentage of early of breastfeeding in
Indonesia is still low [12]. Overall, the percentage of early initiation of breastfeeding in Indonesia between 2007 and 2012 was $49.3 \%$ of all live births, and lower in some provinces, including Aceh Province (Figure 2) [12].

Aceh province is located in the most western part of Indonesia, directly adjacent to the Indian Ocean, Andaman Sea, and Malacca strait [13]. The weather in Aceh is the same as in Indonesia; it is a tropical climate with two seasons, rainy and dry, and the average temperature is $25-32^{\circ} \mathrm{C}[13]$. The total area of the Aceh province is $58,377 \mathrm{~km}^{2}$ and divided into 23 districts, 286 subdistricts, and 6489 villages with a total population in 2012 of around 4.7 million people [13].

The percentage of early initiation of breastfeeding in Aceh province between 2007 and 2012 was $46.4 \%$ of all live births; this is lower than the national percentage (49.3\%) [13]. The data from the Indonesian Ministry of health gave the 
percentage of LBW in Aceh province in 2010 as $11.1 \%$ of all live births [14] which was higher than the national percentage of 9\% [8]. Accordingly the data indicated a higher risk of mortality in Aceh than in other provinces in Indonesia. Since the percentage of LBW is higher, it greatly increases a child's risk of dying during their early month and years of life and early initiation of breastfeeding is expected to decrease the neonatal mortality, especially for the LBW [3].

The high risk of neonatal mortality due to LBW and the lower number of newborns who accept early initiation of breastfeeding were the reasons why the study conducted. This study was a part of a study that determines factors related to neonatal mortality among LBW in Aceh province, Indonesia. The objective of this study was to assess the effects of early initiation of breastfeeding on neonatal mortality among the $\mathrm{LBW}$ in Aceh province, Indonesia.

\section{Methods}

2.1. Study Design. This is a population study based on retrospective unmatched case control study. The reason for the choice of unmatched case control was the difficulty in finding individuals of matching case and control due to the large area of the study, the limited number of cases, and the lack of data or documentation related to this study within the health facility.

2.2. Population. The low birth weight babies who were born between 2010-2012 in Aceh Province, Indonesia

2.3. Inclusion and Exclusion Criteria. Inclusion and exclusion criteria for recruitment in the sample in the quantitative study are shown in Table 1.

2.4. Sample Size. Total number of neonatal death due to LBW between 2009-2010 in Aceh province was 399 cases, including multiple birth and birth weight $<1000$ grams (from 23 districts), that is, 399 cases including multiple birth and birth weight $<1000$ grams. Based on the number of cases, the sample size calculated with formula from Fleiss (2003), and the sample size required for this study was 454 . After added $10 \%$ to compensate for missing or incomplete data, the total sample size this study was 500. The total sample was divided into two groups, consist of: 250 cases (LBW who died in neonatal period) and 250 control (LBW who alive during the neonatal period).

2.5. Study Instrument. The study instruments were questionnaire and medical records. The questionnaire consists of characteristics of the LBW and family and how the family took care of the neonate at home during the neonatal period, including feed, thermal care, and hygienic practice. The questionnaire was created by the researcher and had been tested for validity and reliability on 30 mothers who had LBW infant in the Banda Aceh (one of the districts in Aceh province and is not included as study site). The result of the test was that the questionnaire was valid and reliable as an instrument in this study. The tests were conducted in November 2011.

2.6. Operational Definition of Variables and the Classification. There were 5 variables used in this study; there were neonatal mortality, early initiation of breast feeding, feeding, thermal care, and hygienic practice.

2.6.1. Neonatal Mortality. A live birth with birth weight $<2500$ grams and dying during the first 28 completed days of life.

Classification. 0 = alive: A live birth with birth weight $<2500$ grams and survive during the first 28 completed days of life. 1 = died: A live birth with birth weight $<2500$ grams and dying during the first 28 completed days of life.

2.6.2. Early Initiation of Breastfeeding. The time of initiation of breastfeeding accepted by the baby after birth. The data was taken from the MCH (Maternal and Child Health) book and cohort book in the health facility.

Classification. 0 = accepted of breastfeeding within an hour after birth, and $1=$ Did not accept the breastfeeding within an hour after birth.

2.6.3. Feeding. Food given to neonates for the first 28 days of life or before the neonate died. Classification. $0=$ only fed breastfed. 1 = breastfed and some other foods, or other foods without breastfed.

2.6.4. Thermal Care. The methods used by the family to provide warmth for the neonates were categorized into eight actions, which were delay of the first bath until $>12$ hours after birth, provision of warm clothes, not bathing neonates twice a day, always using blankets, performing kangaroo mother care (KMC), using warm bottles for a minimum period of 1 week or before the neonate died, using bulb lamp for a minimum period of 1 week or before the neonate died, and using fireplace twice a day and for a minimum period of one week. Each action implemented by parent/family was given 1 score. Classification. 0 = Adequate care (if the total score of thermal care between 5-8). 1 = inadequate care (if the total score of thermal care between 0-4).

2.6.5. Hygienic Practice. The attempts to maintain neonatal hygiene were categorized into five actions, which were Did not apply traditional/alcohol ingredients on umbilical cord stump, always put neonate in the clean place (baby crib, mattress or bed), always changed immediately the clothed if were wet or dirty, always boiled the equipment to feed before being used and always wash hands with soap before giving feeding to the neonate (such as: after using the toilet, after cleaning the baby, after doing housework, after returning home from outside, or after doing dirty work). Each action implemented by parent/family was given 1 score. Classification. 0 = Adequate care (if the total score for hygiene 
TABLE 1: Inclusion and exclusion criteria.

\begin{tabular}{lll}
\hline Criteria & Cases & Control \\
\hline & (1) Born alive with birth weight between & (1) Born alive with birth weight between \\
1,001 and 2,499 grams & 1,001 and 2,499 grams \\
(2) Born between 2010 and 2012 on the & Born between 2010 and 2012 on the \\
study site & (3) Survived during the first 28 completed \\
study site & days of life \\
\hline & (3) Dying during the first 28 completed & (1) Moved from study site before or \\
& (1) Moved from study site before or & during data collection \\
during data collection & (2) Presence of congenital abnormalities \\
(2) Presence of congenital abnormalities & (3) Multiple births \\
(3) Multiple births & (4) Hospitalized during neonatal periods \\
(4) Hospitalized during neonatal periods & (5) The neonate was adopted in the \\
& (5) The neonate was adopted in the & neonatal period \\
\end{tabular}

practice between 3 to 5). 1 = Inadequate care (if the total score for hygiene practice between 0 to 2 ).

2.7. Study Site. The study was conducted in 8 of 23 districts in Aceh province. The districts were Aceh Besar, Pidie, Aceh Utara, Lhoksumawe, Aceh Timur, Aceh Tamiang, Bener Meriah, and Aceh Tengah. There were several reasons and considerations for selecting these districts, which were high number of neonatal mortality due to LBW, ease of access to the geographical location of the study site, and availability of transportation and accommodation.

2.8. Data Collection and Procedure. The data about the number of cases in Aceh province was sourced from the Aceh province health office, and the researcher determined the districts to use as the study sites. After receiving permission from the head of Aceh province health office to collect data, the researcher approached the district officials to get information about possible cases for the study. In the district health office, the researcher found the addresses of LBW who dying in the neonatal period (case). Furthermore, the researcher came to sub district through community health center (Puskesmas) to trace the case. In the Puskesmas, the researcher decided on the data to be used as case and control and then recruited enumerators for the home survey. The researcher was assisted by from 1 to 4 enumerators in each subdistrict that had cases, and most of the controls were found in the same subdistrict. If the control was not found in the same subdistrict, the researcher would be looking in another subdistrict in that same district. The enumerator was a midwife who was working in the community health center or village. Before collecting data, the researcher explained about the study to the enumerators and how they should fill in the questionnaire. The data was collected from January to December 2012.

2.9. Data Analysis. The data was analyzed in three steps using Statistical Package for Services Solutions (SPSS) 20.0. Those steps were descriptive analysis, simple logistic regression analysis, and multiple logistic regression analysis (Tables 4 and 5).
TABLE 2: Characteristics of neonates.

\begin{tabular}{lcccc}
\hline \multirow{2}{*}{ Characteristics } & \multicolumn{2}{c}{ Case (250) } & \multicolumn{2}{c}{ Control (250) } \\
& $n$ & $\%$ & $n$ & $\%$ \\
\hline Sex & & & & \\
$\quad$ Female & 101 & 40.4 & 140 & 56 \\
$\quad$ Male & 149 & 59.6 & 110 & 44 \\
Birth weight & & & & \\
$\quad$ 1500-2499 grams & 171 & 68.4 & 243 & 97.2 \\
$\quad$ 1001-1499 grams & 79 & 31.6 & 7 & 2.8 \\
$\quad$ Gestational age & & & & \\
$\quad$ Full term ( $\geq 37$ weeks) & 44 & 17.6 & 103 & 41.2 \\
$\quad$ Preterm $(<37$ weeks $)$ & 206 & 82.4 & 147 & 58.8 \\
\hline
\end{tabular}

\section{Results}

Table 2 shows the characteristics of neonates in the study sample. The characteristics were divided into sex, birth weight, and gestational age when they were born. In the sex characteristic, 149 (59.6\%) neonates in the case group were male and 140 (56\%) neonates in the control group were female. Most neonates in the control group (243 neonates or $97.2 \%)$ and 171 neonates $(68.4 \%)$ in the case group were born at a weight between 1500 and 2499 grams. The gestational age characteristic indicated that 206 or $82.4 \%$ neonates in case group and 147 neonates (58.8\%) in the control group were born $<37$ weeks of gestational age.

Table 3 shows the characteristic of the parents. It can be seen that 2 of 500 mothers who gave birth in the sample of this study died during the neonatal period. 211 or $84.4 \%$ of the mothers in the control group who gave birth to LBW babies were aged between 20 and 35 years, as were 182 or $72.8 \%$ of mothers in the case group. $\mathrm{n}$ the birth interval characteristic, $201(80.4 \%)$ mothers in the control group and 165 (66\%) mother in the case group, giving birth the LBW neonates after 2-5 years from the previous child. 147 (58.8\%) mothers in the control group and $134(53.6 \%)$ mothers in the case group had been giving birth 2-4 times before give birth the LBW neonates who as the sample this study. A majority of mothers in the case group ( 221 or $88.4 \%$ ) and 214 or $85.6 \%$ mothers in the control group have a formal education in the low level 
TABLE 3: Characteristics of family.

\begin{tabular}{|c|c|c|}
\hline \multirow[b]{2}{*}{ Variables } & \multicolumn{2}{|c|}{ Group } \\
\hline & $\begin{array}{c}\text { Case }(250) \\
(\%)\end{array}$ & $\begin{array}{c}\text { Control (250) } \\
(\%)\end{array}$ \\
\hline \multicolumn{3}{|l|}{ Maternal death } \\
\hline Mother dead & $0(0)$ & $2(0.8)$ \\
\hline Mother alive & $250(100.0)$ & $248(99.2)$ \\
\hline \multicolumn{3}{|l|}{ Age of mother } \\
\hline$<20$ or $>35$ years old & $68(27.2)$ & $39(15.6)$ \\
\hline 20-35 years old & $182(72.8)$ & $211(84.4)$ \\
\hline \multicolumn{3}{|l|}{ Birth interval } \\
\hline$<2$ or $>5$ years & $85(34.0)$ & 49 (19.6) \\
\hline $2-5$ years & $165(66.0)$ & $201(80.4)$ \\
\hline \multicolumn{3}{|l|}{ Parity } \\
\hline 1 or $>5$ times & $116(46.4)$ & $103(41.2)$ \\
\hline $2-4$ times & $134(53.6)$ & $147(58.8)$ \\
\hline \multicolumn{3}{|l|}{ Maternal education level } \\
\hline $\begin{array}{l}\text { Elementary school-high } \\
\text { school }\end{array}$ & $221(88.4)$ & $214(85.6)$ \\
\hline Diploma-master's & $29(13.6)$ & $36(14.4)$ \\
\hline \multicolumn{3}{|l|}{ Paternal education level } \\
\hline $\begin{array}{l}\text { Elementary school-senior } \\
\text { high school }\end{array}$ & $228(91.2)$ & $216(86.4)$ \\
\hline Diploma and above & $22(8.8)$ & $34(13.6)$ \\
\hline \multicolumn{3}{|l|}{ Paternal smoking } \\
\hline $\begin{array}{l}\text { Smoker and smoke around } \\
\text { the mother when she is pregnant }\end{array}$ & $219(87.6)$ & $195(78)$ \\
\hline $\begin{array}{l}\text { Not smoker or smoker but did } \\
\text { not smoke around the mother } \\
\text { when she is pregnant }\end{array}$ & $31(12.4)$ & $55(22)$ \\
\hline \multicolumn{3}{|l|}{ Family income } \\
\hline Low income & $107(42.8)$ & $75(30)$ \\
\hline High income & $143(57.2)$ & $175(70)$ \\
\hline Median IDR: $1,500,000,00$ & & \\
\hline
\end{tabular}

(elementary school to high school) when they gave birth to LBW babies.

Most of the fathers had a low level of education when the LBW babies were born, that is, $228(91.2 \%)$ in the case group and $216(86.4 \%)$ in the control group. 219 or $87.6 \%$ of fathers in case group and 195 (78\%) of fathers in the control group were smokers and smoked around the mothers when they are pregnant with the LBW babies. Based on the median income from all the families in this study, it was found that 175 (70\%) of the families in control group and 143 or $57.2 \%$ of families in the case group had a high income level.

The results of simple logistic regression from 4 of the variables, early initiation of breastfeeding, feeding, thermal care, and hygiene practice, showed that early initiation of breastfeeding and feeding were significantly associated with mortality among LBW $(P<0.01)$. Meanwhile, thermal care and hygiene practice were not associated with neonatal mortality for LBW $(P>0.05)$.
To determine the factors for neonatal mortality for the low birth weight, multiple logistic regressions was used. A likelihood ratio test was used for analysis because this study involved unmatched case control. In the multiple logistic regressions, 2 variables had significance in simple logistic regression analysis. The results indicate that early initiation of breastfeeding and feeding were determinant factors of neonatal mortality among LBW neonates in Aceh province, Indonesia. Neonates who were not breastfed within the first hour after birth had around 3 times greater risk of death compared to neonates who were breastfed within the first hour (OR 2.9; CI 95\%: 1.7-4.8). Neonates who obtain not only breast milk during neonatal period (or before death) as the feeding had 8.5 times greater risk of death than neonates who obtained only breast milk (OR 8.5; CI 95\%: 2.89-10.76).

\section{Discussion}

The study showed that feeding was the overwhelming determinant factor of neonatal mortality for the LBW. The neonates, who were fed not only breast milk but other food as well, had 8.5 times greater risk of death than neonates who received only breast milk in the neonatal period. There were some previous studies in which the findings were in line with this study $[11,15]$.

The results of this study found that the early initiation of breastfeeding was one of determinant factors in the mortality of LBW neonates. Those LBW neonates who did not accept breastfeeding within an hour after birth had 2.9 times greater risk of death than those neonates who received breastfeeding within that hour. This result was similar to a study conducted in rural Ghana [11]. That study concluded that $22 \%$ of neonatal deaths could have been averted if all neonates had been breastfed within the first hours of birth. Around 16\% of neonatal deaths could be averted if all neonates got breastfed from the first day. The subjects of the study included the neonates weighing $>3500$ grams who had better chances of survival than the LBW neonates. That could be the reason the ratio was higher than in the present study. The other study conducted in Nepal also came to a similar conclusion [10]. Those LBW neonates who did not receive breastfeeding within the first hour of birth had 4 times greater risk of death than those LBW neonates who received it [10]. The low percentage of LBW as the samples in that study (29.8\% of all samples) could be the reason the results were slightly lower than in the present study.

A qualitative study that was conducted in Aceh province to explore the mother's and family experience related to neonatal care of the LBW neonates found several reasons why mothers did not provide early breastfeeding to their neonates and the reasons why some mothers gave early breastfeeding. Most mothers who did not give early breastfeeding said they did not know that the neonates should be breastfed within an hour and also because it was not in the culture or a widespread custom in their community. other mothers said they did not give early breastfeeding because the condition of the neonates or their mothers (grandmother of the neonate) prohibit for gave breastfed early because of culture and customs. All 
TABLE 4: Simple logistic regression analysis of risk factors the neonatal mortality among low birth weight in Aceh Province.

\begin{tabular}{|c|c|c|c|c|}
\hline \multirow{3}{*}{ Variables } & \multicolumn{2}{|c|}{ Group } & \multirow{3}{*}{$\begin{array}{c}\text { OR } \\
95 \% \text { CI }\end{array}$} & \multirow{3}{*}{$P$} \\
\hline & Case (250) & Control (250) & & \\
\hline & $f(\%)$ & $f(\%)$ & & \\
\hline \multicolumn{5}{|l|}{ Initiation of breastfeeding } \\
\hline Did not accept early initiation of breastfeeding & $219(87.6)$ & $131(52.4)$ & 6.41 & \multirow{2}{*}{$<0.001^{*}$} \\
\hline Accepted early initiation of breastfeeding & $31(12.4)$ & $119(47.6)$ & $(4.0-10.0)$ & \\
\hline \multicolumn{5}{|l|}{ Feeding } \\
\hline Inappropriate care & $230(92 \%)$ & $117(46.8 \%)$ & 13.7 & \multirow{2}{*}{$<0.001^{*}$} \\
\hline Appropriate care & $20(0.8 \%)$ & $133(53.2 \%)$ & & \\
\hline \multicolumn{5}{|l|}{ Thermal care } \\
\hline Inadequate care & $109(43.6)$ & $116(46.4)$ & 0.89 & \multirow{2}{*}{0.529} \\
\hline Adequate care & $141(56.4)$ & $134(53.6)$ & $(0.62-1.27)$ & \\
\hline \multicolumn{5}{|l|}{ Hygienic practice } \\
\hline Inadequate care & $6(2.4)$ & $9(3.6)$ & 0.65 & \multirow{2}{*}{0.435} \\
\hline Adequate care & $244(97.6)$ & $241(96.4)$ & $(0.23-1.87)$ & \\
\hline
\end{tabular}

TABLE 5: Multiple logistic regression analysis of risk factors the neonatal mortality among low birth weight in Aceh Province.

\begin{tabular}{|c|c|c|c|c|}
\hline \multirow{3}{*}{ Variables } & \multicolumn{2}{|c|}{ Group } & \multirow{3}{*}{$\begin{array}{c}\text { OR } \\
95 \% \mathrm{CI}\end{array}$} & \multirow{3}{*}{$P$} \\
\hline & Case $(250)$ & Control (250) & & \\
\hline & $f(\%)$ & $f(\%)$ & & \\
\hline \multicolumn{5}{|l|}{ Initiation of breastfeeding } \\
\hline Did not accept early initiation of breastfeeding & $219(87.6)$ & $131(52.4)$ & 2.9 & \multirow{2}{*}{$<0.001^{*}$} \\
\hline Accepted early initiation of breastfeeding & $31(12.4)$ & $119(47.6)$ & $(1.7-4.8)$ & \\
\hline \multicolumn{5}{|l|}{ Feeding } \\
\hline Inappropriate care & $230(92 \%)$ & $117(46.8 \%)$ & 8.5 & \multirow{2}{*}{$<0.001$} \\
\hline Appropriate care & $20(0.8 \%)$ & $133(53.2 \%)$ & $(4.9-14.8)$ & \\
\hline
\end{tabular}

${ }^{*}$ Significant variable: $P<0.05$.

mothers who gave early breastfeeding within an hour after birth did so because it was suggested by the midwife and was not because of their initiative [16].

This study indicated that there was no significant association between thermal care and hygiene practice with neonatal mortality for the LBW. It contrasts with results from some previous studies [17-19]. The study method and study site are possibilities for the different results. Some factors that give strength to this study are total sample, number of districts as study sites, and the data being collected over 3 years. The study was limited by the lack of complete data in health facility for the cases that were used and having no reference to similar studies in Indonesia.

\section{Conclusion}

This study found that breast milk and the early initiation of breastfeeding were determinant factor of neonatal mortality for the LBW in Aceh Province, Indonesia. A new strategy to promote and improve the number of LBW that accept initiation of breastfeeding and exclusive breastfeeding needed. One of the attempt is organize the annual LBW contest in each sub-district, where the judgment will be based on the acceptance of initiation of breastfeeding and exclusiveness of breastfeeding by the infant and the growth and development of the infant.

\section{Conflict of Interests}

The authors declare that there is no conflict of interests regarding the publication of this paper.

\section{Acknowledgments}

The authors would like to thank the midwives of the eight districts in Aceh province, Indonesia, for their help in collecting data as enumerators in the field. Also their appreciation goes to Aceh province health office and the eight district health offices in Aceh province in giving their permission to conduct this study in their territory.

\section{References}

[1] World Health Organization e-Library of Evidence for Nutrition Actions (eLENA), Early Initiation of Breastfeeding, WHO, 2014, http://www.who.int/elena/titles/early breastfeeding/en/.

[2] B. R. Thapa, "Health factors in colostrum," Indian Journal of Pediatric, vol. 72, no. 7, pp. 579-581, 2005. 
[3] United Nations Children's Fund, Child Info: Monitoring the Situation of Children and Women; Statistic by Area/Child Nutrition, http://www.childinfo.org/breastfeeding.html.

[4] The Global Breastfeeding Initiative for Child Survival( GBICS), The State of Breastfeeding in 33 Countries 2010, IBFAN-ASIA, Delhi, India, 2010.

[5] World Health Organization and United Nations Children's Fund, Low Birth Weight: Country, Regional, Global Estimates, WHO \& UNICEF, New York, NY, USA, 2004.

[6] J. Lawn, B. J. McCarthyand, and S. R. Ross, The Healthy Newborn: A Reference Manual for Program Managers, World Health Organization (WHO), Center for Disease Control \& Prevention (CDC), California Children Health Initiative (CCHI) and Care, 2005.

[7] United Nations Children's Fund, Level \& Trends in Child Mortality, http://www.childinfo.org/files/Child_Mortality_Report_ 2012.pdf.

[8] United Nations Children's Fund, Improving Child Nutrition: The Achievable Imperative for Global Progress, 2013, http://www.unicef.org/nutrition/index_68661.html.

[9] Departemen Kesehatan Republik Indonesia, Report on Result of National Basic Health Research (RISKESDAS) 2007, Departemen Kesehatan Republik Indonesia, Jakarta, Indonesia, 2008.

[10] L. C. Mullany, J. Katz, Y. M. Li et al., "Breast-feeding patterns, time to initiation, and mortality risk among newborns in Southern Nepal," Journal of Nutrition, vol. 138, no. 3, pp. 599603, 2008.

[11] K. M. Edmond, C. Zandoh, M. A. Quigley, S. Amenga-Etego, S. Owusu-Agyei, and B. R. Kirkwood, "Delayed breastfeeding initiation increases risk of neonatal mortality," Pediatrics, vol. 117, no. 3, pp. e380-e386, 2006.

[12] Statistics Indonesia, National Population and Family Planning Board, and Indonesia Ministry of Health and United State Agency for International Development, Indonesia Demographic and Health Survey 2012, Jakarta. Indonesia, 2013.

[13] Dinas Kesehatan Provinsi Aceh, Profil Kesehatan Provinsi Aceh Tahun 2012, Banda Aceh, 2013.

[14] Kementerian Kesehatan Republik Indonesia and Badan Penelitian dan Pengembangan Kesehatan, Riset Kesehatan Dasar (Riskesdas) 2010, Kementerian Kesehatan Republik Indonesia, Badan Penelitian dan Pengembangan Kesehatan, Jakarta, Indonesia, 2010.

[15] S. L. Huffman, E. R. Zehner, and C. Victora, "Can improvements in breast-feeding practices reduce neonatal mortality in developing countries?" Midwifery, vol. 17, no. 2, pp. 80-92, 2001.

[16] Satrinawati, Determinant Factor of Neonatal Mortalityamong Low Birth Weight Neonates in Aceh Province, Indonesia, Medicine Faculty, National University of Malaysia, Kuala Lumpur, Malaysia, 2014.

[17] A. T. Bang, S. B. Baitule, H. M. Reddy, M. D. Deshmukh, and R. A. Bang, "Low birth weight and preterm neonates: can they be managed at home by mother and a trained village health worker?" Journal of Perinatology, vol. 25, no. 1, pp. S72-S81, 2005.

[18] N. L. Sloan, S. Ahmed, S. N. Mitra et al., "Community-based kangaroo mother care to prevent neonatal and infant mortality: a randomized, controlled cluster trial," Pediatrics, vol. 121, no. 5, pp. e1047-e1059, 2008.

[19] V. Rhee, L. C. Mullany, S. K. Khatry et al., "Maternal and birth attendant hand washing and neonatal mortality in southern Nepal," Archives of Pediatrics and Adolescent Medicine, vol. 162, no. 7, pp. 603-608, 2008. 


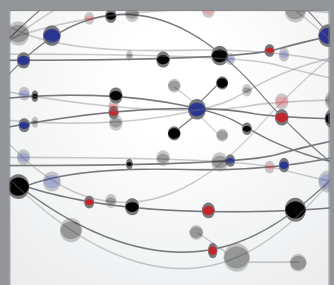

The Scientific World Journal
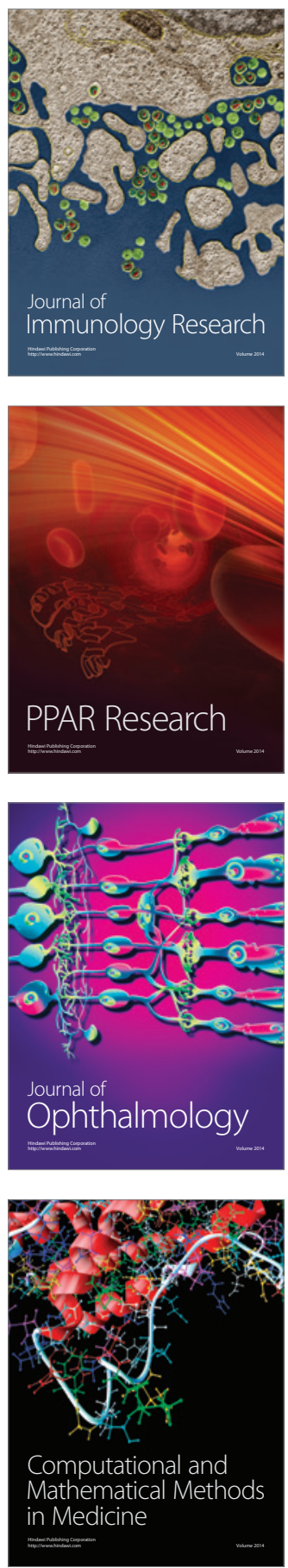

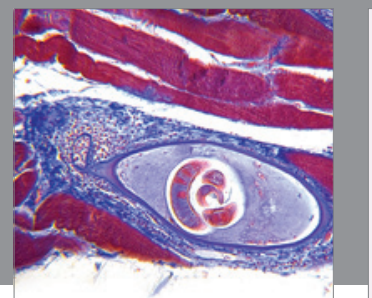

Gastroenterology

Research and Practice
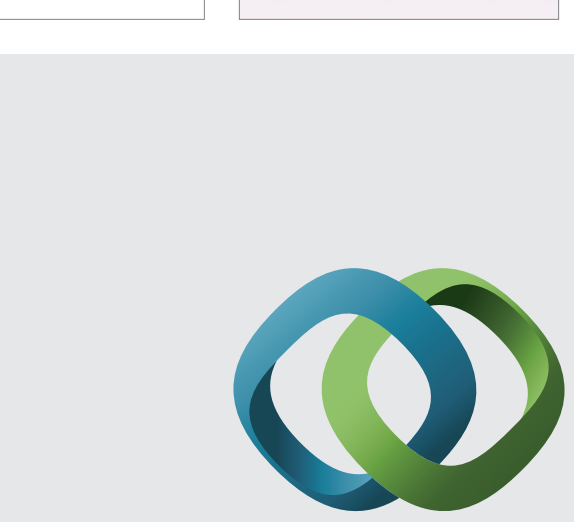

\section{Hindawi}

Submit your manuscripts at

http://www.hindawi.com
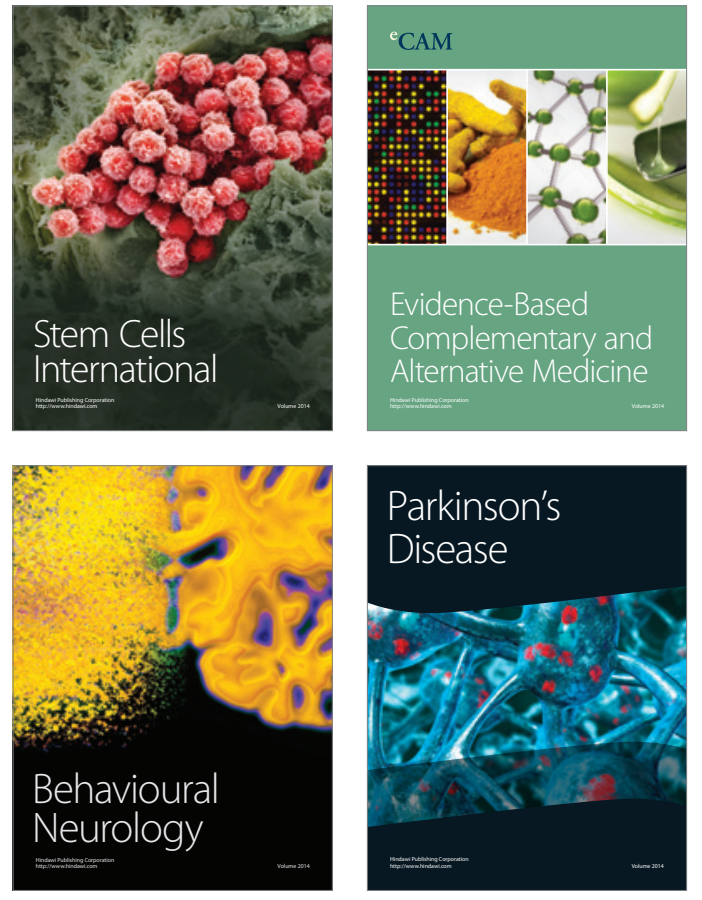
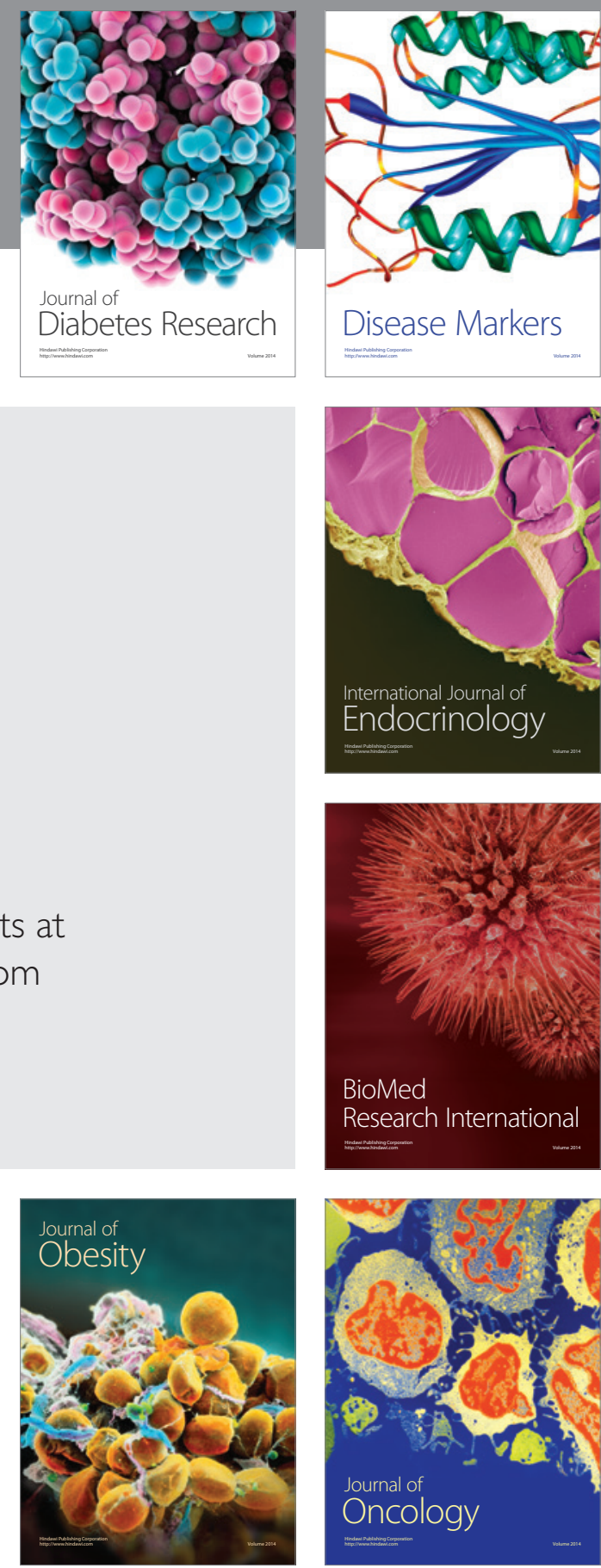

Disease Markers
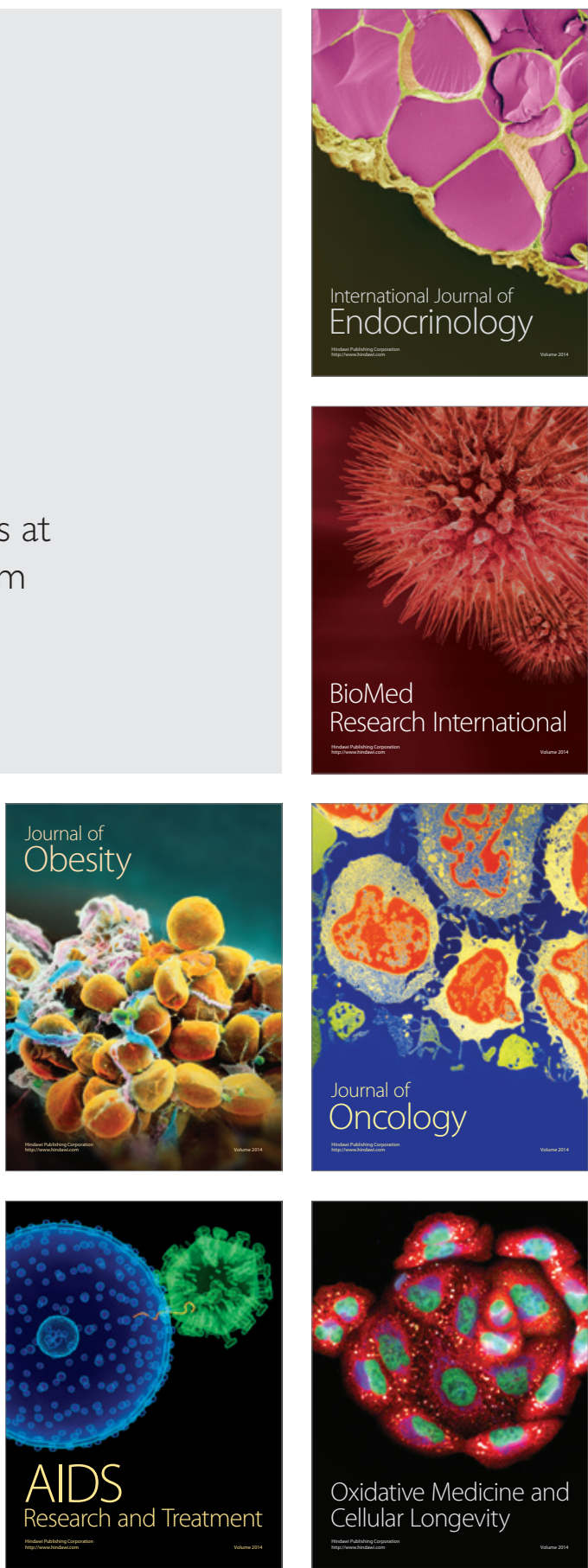